\title{
Economic Burden of Rheumatoid Arthritis In Iran: A Societal Perspective Economic Burden of R.A.
}

\author{
Mehdi Rezaee \\ Kerman University of Medical Sciences \\ Farhad Lotfi \\ Shiraz University of Medical Sciences \\ Ahmad Gholami \\ Shiraz University of Medical Sciences \\ Jassem Azizpoor \\ Shiraz University of Medical Science \\ Elham Aflaki \\ Shiraz University of Medical Sciences \\ Afsaneh Vazin \\ Shiraz University of Medical Sciences \\ Khosro Keshavarz ( $D$ khkeshavarz2007@gmail.com ) \\ Shiraz University of Medical Sciences
}

\section{Research Article}

Keywords: Cost of Illness, Economic Burden, Direct Medical Cost, Direct Non-Medical Costs, Indirect Costs, Rheumatoid Arthritis.

Posted Date: January 20th, 2022

DOI: https://doi.org/10.21203/rs.3.rs-1275686/v1

License: (c) (i) This work is licensed under a Creative Commons Attribution 4.0 International License. Read Full License 


\section{Abstract}

Background: Rheumatoid arthritis (RA) is a progressive, chronic systemic inflammatory disease and impose a significant economic burden on patients and societies if not controlled. This study aimed to determine the economic burden of RA in southern Iran in 2019.

Methods: This economic burden study was carried out as cross-sectional research in 2019 in southern Iran, in which 765 patients were included. The prevalence-based and bottom-up approaches were also used to prepare the cost information and calculate the costs, respectively. The human capital approach was used to calculate the indirect costs as well.

Results: The results showed that the economic burden of RA in Iran was \$ 3,744,967,993 PPP in 2019. In addition, the mean annual costs of RA per patient in remission, low, and moderate-to severe states and the total cost were $\$ 11,925.98, \$$ 11,887.49, \$12,803.45, and \$12,155.08 PPP, respectively in 2019.

Conclusions: RA imposed a significant economic burden on the community and patients, and DMC, especially the cost of drugs, were the most important component. It is suggested to provide necessary facilities to produce RA drugs in the country and expand home care services in order to reduce the economic burden.

\section{Background}

Rheumatic diseases are chronic progressive diseases that damage the locomotor system, lead to disability, and, thus, reduce the patient's quality of life. Inflammatory rheumatic diseases are especially dangerous to health [1]. The most common inflammatory rheumatic diseases are rheumatoid arthritis (RA) and spondyloarthropathy. Progressive joint injury, pain, disability, and premature mortality are some characteristics of RA, especially if not treated in a timely manner [2]. The patients often suffer from symptoms that may be objectively difficult to quantify (e.g., fatigue), while affecting work performance, and are not often overlooked by employers [3]. In RA, the disability due to the disease is more important and frequent than mortality. Pain, dysfunction, fatigue, and depression are among the common symptoms of the disease, associated with a significant reduction in the quality of life [4].

The prevalence of RA varies in different countries. For instance, the prevalence rate of the disease in the United States increased from $0.41 \%$ in 2004 to $0.54 \%$ in 2014 [5]. In Germany, it was estimated at $1.4 \%$ in 2013 [6]. The results of a systematic review in 2017 showed that the debilitating condition could affect $0.5-2.4 \%$ of the world's population [7]. In addition, the prevalence of RA in 2016 was reported to be $0.37 \%$ in Iran [8].

RA is a chronic progressive autoimmune disease that imposes a significant economic burden on the patients and their families [9]. The total annual economic cost of RA in 2008 was estimated at $€ 45.3$ billion in Western Europe and $€ 41.6$ billion in the United States[10]. According to the studies conducted in recent years, the economic burden of the disease has increased significantly in such a way that the annual economic burden of RA in the United States in 2005 was \$ 19.3 billion, of which 56\% (\$10.9 billion) was that of indirect costs [11]. However, it was estimated at \$ 48 billion in 2015 [12]. A study conducted in Germany in 2017 showed that direct costs of RA had increased in the last decade [13].

Over the past 15 years, RA management has changed through the use of early invasive therapies as well as biological treatments. Common RA treatments include traditional disease-modifying antirheumatic drugs (DMARDs) such as Methotrexate, as well as newer and more effective biological therapies [14]. The first biological agents are tumor necrosis factors (TNFs) inhibitors, including Etanercept, Infliximab, Adalimumab, and Anakinra [15]. TNF inhibitors are a class of biopharmaceuticals that can be used to treat Crohn's disease, ulcerative colitis, rheumatoid arthritis, ankylosing spondylitis, psoriatic arthritis, plaque psoriasis, and / or juvenile idiopathic arthritis [16]. Introducing TNF inhibitors, which are able to improve symptoms and slow disease progression, will lead to reduced surgery and hospitalization costs. They will also reduce the productivity lost due to absence from work and early retirement [17]. 
Considering different medical costs of RA and, thus, different financial and economic burden on the health system, and due to the limited knowledge about its economic burden, and since the researchers could not find any studies on the economic burden of the disease in Iran, the present study was conducted to determine the economic burden of RA.

\section{Methods}

This cross-sectional cost of illness study was carried out on RA patients referring to the medical centres affiliated to Shiraz University of Medical Sciences in Fars province, Iran, in 2019. In this study, the prevalence-based model was used to calculate the costs. Prevalence-based studies deal with the total number of cases in a given period of time (usually one year). In this approach, the economic cost of the existing cases of the disease is estimated during a given period [18]. Therefore, all the patients with rheumatoid arthritis who referred to the referral rheumatology hospitals affiliated to Shiraz University of Medical Sciences (Hafez Hospital, Saadi Hospital, and the clinics affiliated to these two hospitals) in 2019 and had medical records and were also willing to participate in the study were included through census $(\mathrm{N}=765)$.

The societal perspective was used to extract the costs in this study. From this perspective, relevant costs included direct medical costs (DMCs), direct non-medical costs (DNMCs), and indirect costs (ICs). The DMCs were collected retrospectively from January 1 to December 31, 2019, using the cost collection form and by referring to the aforementioned hospitals. The DNMCs and ICs were also collected using the cost collection form and the patients' self-declaration.

In order to increase the accuracy and precision of the data on DMCs, the subjects' inpatient and outpatient medical records were used. In addition, to obtain an accurate analysis of the costs, the direct total costs of the drugs (price without subsidies), Physicians' visits, Laboratory tests, Physiotherapy, Diagnostic services, and Hospitalization were separately determined for the patients in 2019.

The DNMC-related information was obtained through interviews with the patients. Since a large percentage of the patients referred to the medical centres were living out of Shiraz, items such as the cost of traveling to the centres to receive medical services, as well as accommodation and food costs were regarded as DNMC components for the patients and their companions.

The human capital approach was also used to calculate the ICs [19]. The ICs for each patient were calculated based on the average daily income lost due to the patient's sickness absence and sick leave for hospitalization or disease follow-up, and the average daily income lost for each companion or caregiver due to absence from work to accompany or care for the patient. In the present study, the individuals' wages were used to calculate the lost income. In case of the housewives and students aged 15-65 years, the daily wage determined by the Ministry of Labour (according to the reports of the Labour Department in 2019 amounting to \$22.9 PPP) was used as the mean daily wage [20].

To calculate the costs in this study, a bottom-up approach was used, in which the resources used by each person were measured. Thus, this method could reveal the differences between the patients in terms of treatment [21].

It is noteworthy that in the present study, all the costs were converted into dollars (PPP) using the exchange rate of each dollar equal to 22,075 Rials in 2019 [22].

Estimating the number of RA patients requires the prevalence data in the country. Accordingly, the prevalence rate of the disease around the country was $0.37 \%$ [8] in 2016, and regarding the incidence and mortality rates of RA, its prevalence rate in 2019 could be estimated at $0.37 \%$. Thus, considering the population of 83.27 million in Iran in 2019 [23], the total number of RA patients was estimated at 308,099 in the country.

Finally, after collecting the data on the prevalence rate of RA, the population, and the mean cost per patient in the present study, the economic burden of RA in Iran was calculated using the following formula [24]. 
Economic Burden: Total cost per patient (DMCs + DNMCs + ICs) × estimated number of patients with RA in Iran

\section{Sensitivity Analysis}

To conduct the one-way sensitivity analysis, a study carried out in the country in which a prevalence of $0.37 \%$ ( $95 \% \mathrm{Cl}$ : $0.29-0.46 \%$ ) had been reported was used [8]. Hence, $0.29 \%$ and $0.46 \%$ were considered as the low and high prevalence limits, respectively.

\section{Results}

A total of 765 patients at different stages of RA (440 patients in Remission, 120 patients in Low, and 205 patients in Moderate to Severe states) were included in this study. Table 1 summarizes the descriptive results classified according to the disease stages and based on patients' gender, age, occupational status, type of insurance coverage, and place of residence. According to Table 1, most of the patients were female $(77.12 \%)$ and housewives $(62.09 \%)$, and all the patients had an insurance coverage. In addition, the majority of the patients were 15-65 years of age (90.2). In economic studies, ages 15-65 years are considered productive ages and, thus, are economically important.

Table 1: Demographic characteristics of the patients studied in $2019(\mathrm{~N}=765)$ 


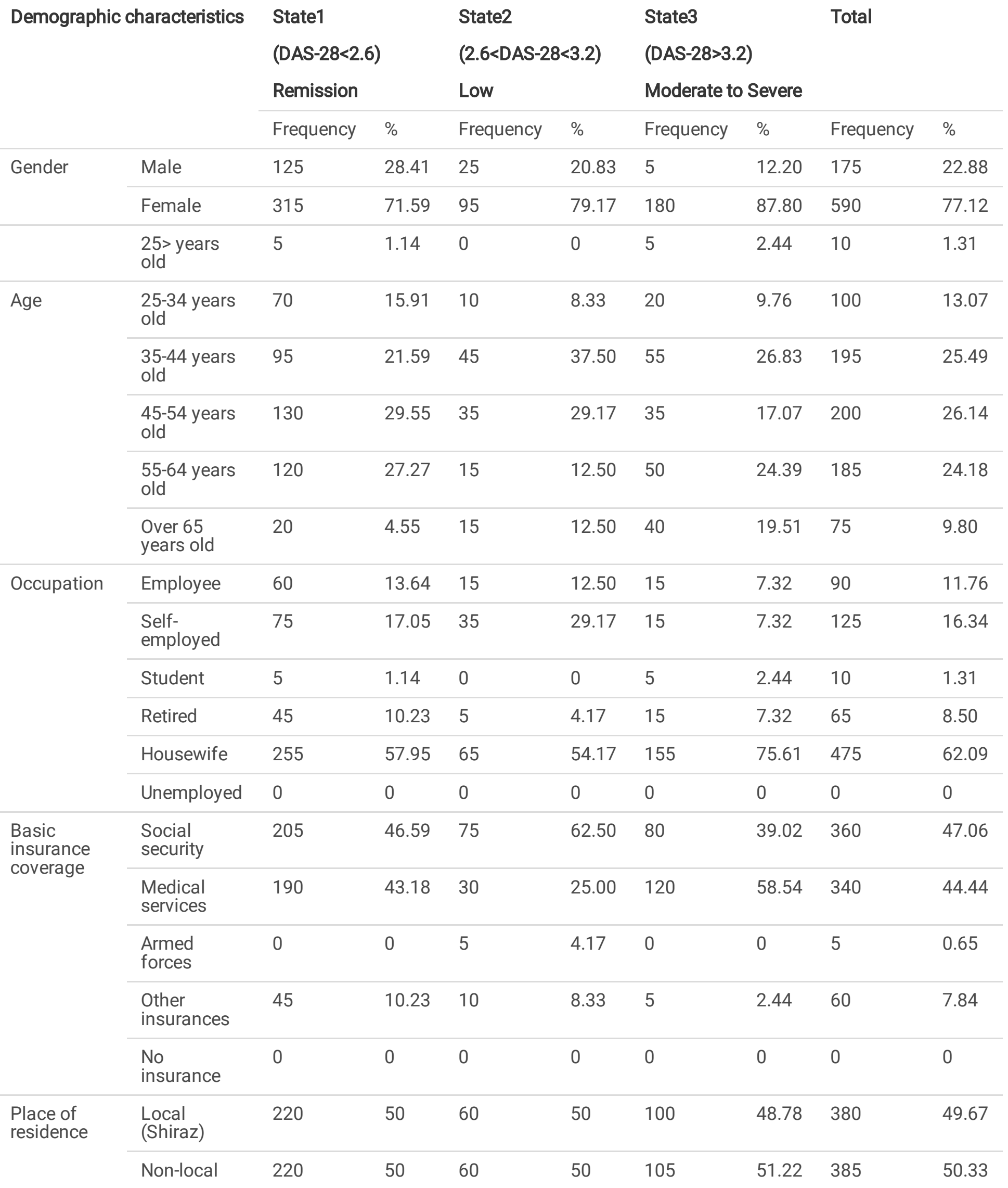

Table 2 and Figure 1 show the mean costs of the patients with RA in three disease states. According to this Table, the mean DMCs of the patients in Remission, Low, and Moderate to Severe states were $\$ 10,430.05, \$ 9,498.58$, and $\$ 10,344.98$, 
respectively, while the DNMCs were $\$ 1,324.31, \$ 2,187.62$, and $\$ 2,259.92$, respectively, and the ICs were $\$ 171.63$, $\$ 201.28$, and $\$ 198.55$, respectively. Furthermore, the cost of purchasing the main drug was the highest DMC in the patients in all three disease states (\$ 8,396.19 in Remission, \$ 7,620.71 in Low, and \$ 8,169.43 in Moderate to Severe states).

In general, according to the information in Table 2, the total annual costs per patient in Remission, Low, and Moderate to Severe states were $\$ 11,925.98, \$ 11,887.49$, and $\$ 12,803.45$, respectively, suggesting that although the difference between the disease states was not great, the costs were generally lower in the Low state.

Table 2: Mean annual costs per patient with RA in Remission, Low, and Moderate to Severe states (based on purchasing power parity (PPP))

\begin{tabular}{|c|c|c|c|c|c|c|c|c|}
\hline States & \multicolumn{2}{|c|}{$\begin{array}{l}\text { State1 } \\
\text { (DAS-28<2.6) }\end{array}$} & \multicolumn{2}{|c|}{$\begin{array}{l}\text { State2 } \\
(2.6<\text { DAS-28<3.2) }\end{array}$} & \multicolumn{2}{|c|}{$\begin{array}{l}\text { State3 } \\
(\text { DAS-28>3.2 ) }\end{array}$} & \multicolumn{2}{|l|}{ Total } \\
\hline \multirow[t]{2}{*}{ Costs } & \multicolumn{2}{|l|}{ Remission } & \multicolumn{2}{|l|}{ Low } & \multicolumn{4}{|c|}{ Moderate to Severe } \\
\hline & $\begin{array}{l}\text { Mean } \\
\text { costs } \\
\text { (PPP) }\end{array}$ & Percent & $\begin{array}{l}\text { Mean } \\
\text { costs } \\
\text { (PPP) }\end{array}$ & Percent & $\begin{array}{l}\text { Mean } \\
\text { costs } \\
\text { (PPP) }\end{array}$ & Percent & $\begin{array}{l}\text { Mean } \\
\text { costs } \\
\text { (PPP) }\end{array}$ & Percent \\
\hline \multicolumn{9}{|l|}{ Direct Medical Costs } \\
\hline Physicians' visits & 167.92 & 1.61 & 162.43 & 1.71 & 197.59 & 1.91 & 178.89 & 1.74 \\
\hline Main medicines & $8,396.19$ & 80.50 & $7,620.71$ & 80.23 & $8,169.43$ & 78.97 & $8,198.65$ & 79.90 \\
\hline Laboratory tests & 603.90 & 5.79 & 585.11 & 6.16 & 710.70 & 6.87 & 643.72 & 6.27 \\
\hline $\begin{array}{l}\text { Physiotherapy \& } \\
\text { other services costs }\end{array}$ & 420.33 & 4.03 & 366.65 & 3.86 & 471.73 & 4.56 & 425.84 & 4.15 \\
\hline Diagnostic services & 278.48 & 2.67 & 269.76 & 2.84 & 326.90 & 3.16 & 296.55 & 2.89 \\
\hline Hospitalization & 563.22 & 5.40 & 493.93 & 5.20 & 468.63 & 4.53 & 517.50 & 5.04 \\
\hline Total & $10,430.05$ & 87.46 & $9,498.58$ & 79.90 & $10,344.98$ & 80.80 & $10,261.14$ & 84.42 \\
\hline \multicolumn{9}{|c|}{ Direct Non-Medical Costs } \\
\hline Transportation & 769.82 & 58.13 & $1,253.29$ & 57.29 & $1,267.75$ & 56.10 & 979.09 & 57.24 \\
\hline Accommodation & 310.29 & 23.43 & 484.99 & 22.17 & 513.55 & 22.72 & 392.16 & 22.93 \\
\hline Meals & 244.20 & 18.44 & 449.34 & 20.54 & 478.62 & 21.18 & 339.20 & 19.83 \\
\hline Total & $1,324.31$ & 11.10 & $2,187.62$ & 18.40 & $2,259.92$ & 17.65 & $1,710.45$ & 14.07 \\
\hline \multicolumn{9}{|l|}{ Indirect Costs } \\
\hline Lost Revenue & 171.63 & 1.44 & 201.28 & 1.69 & 198.55 & 1.55 & 183.49 & 1.51 \\
\hline Total Costs & $11,925.98$ & 100 & $11,887.49$ & 100 & $12,803.45$ & 100 & $12,155.08$ & 100 \\
\hline
\end{tabular}

Considering the number of patients in the country estimated using the prevalence rate, and based on the mean costs extracted from the results of the present study, the DMC, DNMC, and IC as well as the estimated economic burden on all the patients with RA in Iran are presented in Figure 2 and Table 3. Thus, the mean cost of RA patients in Iran was \$ $3,744,967,993$ PPP in 2019. The results also showed that DMCs accounted for the bulk of the total economic burden of RA in the country $(84.42 \%$ of the total costs).

Table 3: Estimation of the total annual costs of RA patients in Iran in 2019 


\begin{tabular}{lllllllll}
\multirow{2}{*}{$\begin{array}{l}\text { Number of patients in } \\
\text { Iran }\end{array}$} & \multicolumn{2}{c}{ DMC } & \multicolumn{2}{c}{ DNMC } & \multicolumn{2}{c}{ IC } & \multicolumn{3}{c}{ COI } \\
\cline { 2 - 9 } & Mean & $\%$ & Mean & $\%$ & Mean & $\%$ & Mean & $\%$ \\
\hline 308,099 & $3,161,446,973$ & 84.42 & $526,987,935$ & 14.07 & $56,533,086$ & 1.51 & $3,744,967,993$ & 100
\end{tabular}

To do the one-way sensitivity analysis, the number of RA patients was considered variable according to the low and high prevalence limits reported in Iran, and the cost components per patient were assumed constant. The total cost was then calculated, the results of which are presented in Table 4.

Table 4: Sensitivity analyses for DMCs, DNMCs, ICs, and total costs of RA patients in Iran in 2019

\begin{tabular}{|c|c|c|c|c|c|c|c|c|c|}
\hline \multirow{2}{*}{$\begin{array}{l}\text { One-way } \\
\text { Sensitivity } \\
\text { analysis } \\
\text { (PPP) }\end{array}$} & \multirow{2}{*}{$\begin{array}{l}\text { Number } \\
\text { of } \\
\text { patients } \\
\text { in Iran }\end{array}$} & \multicolumn{2}{|l|}{ DMC } & \multicolumn{2}{|l|}{ DNMC } & \multicolumn{2}{|l|}{ IC } & \multicolumn{2}{|l|}{ COI } \\
\hline & & Mean & $\%$ & Mean & $\%$ & Mean & $\%$ & Mean & $\%$ \\
\hline $\begin{array}{l}\text { Lower } \\
\text { limit }\end{array}$ & 241,483 & $2,477,890,871$ & 84.42 & $413,044,597$ & 14.07 & $44,309,716$ & 1.51 & $2,935,245,184$ & 100 \\
\hline $\begin{array}{l}\text { Upper } \\
\text { limit }\end{array}$ & 383,042 & $3,930,447,588$ & 84.42 & $655,174,189$ & 14.07 & $70,284,377$ & 1.51 & $4,655,906,153$ & 100 \\
\hline
\end{tabular}

\section{Discussion}

The costs of treating RA patients have increased rapidly in recent years. The discovery of new drugs over the past few years has made the treatment of this disease more complex and expensive, and although the drugs are very effective, they are associated with significant costs $[25,26]$. However, reduced hospital admission rates, better functional status, and lower incidence of disability and absenteeism offset a large portion of pharmaceutical costs [13]. Hence, due to the lack of a comprehensive study on the economic burden of RA in Iran, the present research was carried out to determine the economic burden of RA on the patients referred to the medical centres affiliated to Shiraz University of Medical Sciences in southern Iran in 2019.

The results of this study indicated that the economic burden of RA was $\$ 3,744,967,993$ PPP $(2,935,245,184-4,655,906,153)$. In their study in Italy, Mennini et al. (2017) estimated the economic burden of RA at 2 billion euros [27], which is consistent with the results of the present study. In addition, Birnbaum et al. (2013) in the United States concluded that the economic burden of RA was $\$ 39$ billion [11], which is inconsistent with the results of the present study. One reason for the inconsistency could be the addition of the cost of premature deaths as well as the intangible costs, accounting for $80 \%$ of the total costs.

The economic burden of RA alone was about $4.029 \%$ of the total health expenditures in 2019. The total cost of the health system in Iran was $\$ 93$ PPP billion in 2019 , accounting for $8.66 \%$ of the GDP $[28,29]$.

In addition, according to the results of the present study, the mean costs of the disease per patient were $\$ 11,925.98$, $\$ 11,887.49, \$ 12,803.45$, and \$12,155.08 PPP in Remission, Low, and Moderate to Severe status and Total, respectively. In this regard, the results are consistent with those of the studies by HU et al. (2018) in China[30], Huscher et al. (2015) in Germany [13], Malhan et al. (2012) in Turkey [31], and Ruof et al. (2003) in Germany [32].

The results also showed that DMCs were the greatest total treatment costs, accounting for $87.46 \%, 79.90 \%, 80.80 \%$, and $84.42 \%$ of the total costs of the disease in Remission, Low, Moderate to Severe, and Total, respectively, suggesting that DMCs were the most important cost components for the patients with RA. Furthermore, it was found out that the highest share of DMCs was that of purchasing the main drug $(80.50 \%, 80.23 \%, 78.97 \%$, and $79.90 \%$ of the total direct medical costs at Remission, Low, and Moderate to Severe states and Total, respectively), the reason for which could be the high price of the drugs in Iran. In this study, the DNMCs accounted for $11.10 \%, 18.40 \%, 17.65 \%$, and $14.07 \%$ of the total costs of the 
disease in Remission, Low, and Moderate to Severe states, and Total, respectively. Hsieh et al. (2020) conducted a systematic research examining 72 studies carried out from 2000 to 2019 on the economic burden of RA, and stated that the cost of the drugs was a major component of direct costs, and the costs increased over time [26]. In a study in China examining the burden of arthritis from a societal perspective, Hu et al. (2018) concluded that the mean direct costs were $\$$ $2,559.06 \pm 1,917.21$ per patient a year, and the costs of purchasing the drugs accounted for over $50 \%$ of the total costs (\$ $1,898.15 \pm 1,283.89)$. On the other hand, age and income were significantly associated with indirect and intangible costs[30]. In a study on 689 patients in Turkey, Hamuryudan et al. (2016) examined the direct and indirect costs of arthritis and showed that the mean annual direct and indirect costs were $€ 4,954$ (median $€ 1805$ ) and $€ 2,802$ (median $€ 608$ ) per year. Drug purchase costs accounted for over $50 \%$ of direct costs (average $€ 2,777$; median $€ 791$ ), second to which were the RA-related consulting costs (average, $€ 1,600$; median, $€$ 696)[33]. Michaud et al. (2003) in the US examined the direct costs of RA and showed that the mean total costs of annual direct medical care in 2001 was $\$ 9,519$ per RA patient. Drug costs were $\$ 6,324$ ( $66 \%$ of the total costs), while hospitalization costs were only $\$ 1,573(17 \%)$. About $25 \%$ of the patients underwent biological treatment. The mean total direct costs for the patients receiving biological agents were $\$ 19,016$ a year, while the costs for those not receiving biological therapy were $\$ 6,164$. In addition, direct medical costs of the RA patients who were in the worst quarter in terms of functional status were $\$ 5,022$ more than the expenses incurred in the best quarter, but the costs decreased in all groups after the age of 65[34]. In this respect, the results are consistent with the present study.

However, Naqvi et al. (2020) conducted a study on 358 patients in Pakistan and indicated that the total annual costs of arthritis were $\$ 891.83$, of which the mean costs of visits and physiotherapy sessions were $\$ 72.05$ and $\$ 419.07$, respectively. On average, the costs of drugs and medical devices were estimated at $\$ 63.25$ and $\$ 49.13$, respectively. Diagnostic and laboratory costs were $\$ 12.28$, and the costs of travel were $\$ 40.95$. Finally, the direct costs of RA management were $\$ 235.1$. The results showed that physiotherapy accounted for the highest percentage of costs, and drugs accounted for $7.1 \%$ of the costs, and this is inconsistent with the results of the present study [35]. Catay et al. (2012) conducted a study on 165 patients in Argentina and found that the mean DMC and DNMC costs were $\$ 1,862$ and $\$ 222$, respectively. On the other hand, the mean ICs were $\$ 1,008$ and the mean total annual cost was $\$ 3,093$. Hospitalization accounted for $73 \%$ of the total DMCs, while medications and outpatient procedures accounted for $16 \%$ and $8 \%$ of the total DMCs, respectively. The results differ from those of the present study, the reason for which could be the high costs of hospitalization in that country [36].

The present study also showed that ICs accounted for the lowest total treatment costs and that they were $1.44 \%, 1.69 \%$, $1.55 \%$, and $1.51 \%$ of the total costs in Remission, Low, and Moderate to Severe status and Total, respectively. The results of this study are consistent with those of the studies by Xu et al. (2014) in China [37] and Osiri et al. (2007) in Thailand [38]. However, in a systematic review, Hsieh et al. (2020) showed that indirect costs were primarily related to absenteeism and disability, accounting for $39 \%-86 \%$ of the total costs. Also, the indirect costs reported were highly sensitive to the estimation approach [26]. This is different from our study, one of the reasons for which could be the difference in the approaches used to estimate the costs. According to Zhu et al. (2011) who conducted a study on RA patients in Hong Kong, the mean total costs of RA were $\$ 9,286$ per patient, of which more than $60 \%$ was related to ICs due to the productivity loss [39]. This might be due to the higher wages in Hong Kong. In their study, Filipovic et al. (2011) showed that productivity reduction and related costs varied in different studies, but all studies showed that RA associated with significant direct costs. They also argued that economic analyses that eliminated indirect costs underestimated the full economic impact of RA. This is inconsistent with the present study in which the indirect costs had a low share. Nevertheless, as mentioned, it is generally better to include ICs in the analyses to provide a more accurate estimate of the disease. However, it was stated that the methods used to calculate productivity loss had a significant impact on the results of IC analysis and that they should be carefully selected when designing such studies [40]. This could be one of the reasons why the ICs were different in this study. 
One limitation of the present study was the self-report of the patients or their companions about DNMCs and ICs because they were more likely to forget or approximate some of the costs. In addition, due to the lack of accurate evidence on the number of RA patients in Iran, the opinions of some of the best experts in this field were used in the present study. It is worth mentioning that intangible costs were not calculated in this study due to the inability to measure them accurately.

\section{Conclusions}

In general, the results showed that RA could impose a heavy economic burden on the health care system, insurance system, and the patients themselves due to its relatively high prevalence in Iran and in the world, being chronic and needed for lifelong treatment and the treatment costs. According to the results of the present study, DMCs accounted for the highest costs, the largest share of which were the costs of drug purchase.

According to the obtained results and in order to reduce the economic burden of RA, it is suggested that health managers and policy makers due to the high drug purchase costs and high prices of foreign drugs, it is suggested to provide necessary facilities for the production of these drugs in the country.

\section{List Of Abbreviations}

RA: Rheumatoid Arthritis, TNF: Tumour Necrosis Factor, DMARDs: Disease Modifying Anti Rheumatoid Drugs, DMC: Direct Medical Costs, DNMC: Direct Non-Medical Costs, IC: Indirect Costs, PPP: Purchasing Power Parity.

\section{Declarations}

\section{- Ethics approval and consent to participate}

All data are collected and handled in accordance with the relevant privacy protection guidelines. According to Iran law, the study did not fall under the remit of the Medical Research Involving Human Subjects Act and no approval by a medical ethics committee was necessary. Verbal consent was obtained from respondents who completed a questionnaire anonymously, and their response expressed their willingness to participate. Written consent was obtained from participants to the cognitive interviews

\section{- Consent for publication:}

All participants completed a consent form, stating that they were well-informed about the Content of questionnaires and that they agreed upon the publication of anonymized data.

\section{- Availability of data and material:}

The datasets generated and analyzed during the current study are not publicly available because they contain information that could compromise the privacy of research participants, but are available from the corresponding author upon reasonable request.

\section{- Competing interests:}

The authors declare no competing interests.

\section{- Funding:}

This research did not receive any specific grant from funding agencies in the public, commercial, or not-for-profit sectors.

\section{- Authors' contributions:}


M.R.: Conceptualization, Methodology, Data curation, Software, Supervision, Validation, Writing - review \& editing

F.L.: Conceptualization, Methodology, Data curation, Software, Supervision, Validation, Roles/Writing - original draft

A.Gh.: Conceptualization, Data curation, Methodology, Supervision, Validation, Writing - review \& editing.

J.A.: Data curation, Methodology, Software, Validation, Writing - review \& editing.

E.A.: Conceptualization, Methodology, Supervision, Validation, Writing - review \& editing.

A.V.: Conceptualization, Methodology, Validation, Writing - review \& editing.

Kh.K.: Conceptualization, Data curation, Methodology, Software, Project administration, Investigation, Supervision, Validation, Writing - review \& editing.

\section{- Acknowledgements:}

This Manuscript is retrieved from Pharmacy thesis that was supported and approved by Shiraz University of Medical Sciences with the grant No. 97-01-07-18106 and ethical code IR.SUMS.REC.1399.100. The authors would like to thank Shiraz University of Medical Sciences, Shiraz, Iran and also Center for Development of Clinical Research of Nemazee Hospital and Dr. Amir Yousef Farahmandi for editorial assistance.

\section{References}

1. Scott, D.L., F. Wolfe, and T.W.J. Huizinga, Rheumatoid arthritis. Lancet, 2010. 376: p. 1094-1108.

2. Modena, V., G. Bianchi, and D. Roccatello, Cost-effectiveness of biologic treatment for rheumatoid arthritis in clinical practice: An achievable target? Autoimmunity Reviews, 2013. 12: p. 835-838.

3. Connolly, D., et al., Impact of Fatigue in Rheumatic Diseases in the Work Environment: A Qualitative Study. Int J Environ Res Public Health, 2015. 12: p. 13807-13822.

4. Malm, K., et al., Quality of life in patients with established rheumatoid arthritis: A phenomenographic study. SAGE Open Med, 2017. 5: p. 1-8.

5. Hunter, T.M., et al., Prevalence of rheumatoid arthritis in the United States adult population in healthcare claims databases, 2004-2014. Rheumatol Int, 2017. 37: p. 1551-1557.

6. Hense, S., et al., Prevalence of rheumatoid arthritis in Germany based on health insurance data : Regional differences and first results of the PROCLAIR study. Z Rheumatol, 2016. 75: p. 819-827.

7. McDougall, C., K. Hurd, and C. Barnabe, Systematic review of rheumatic disease epidemiology in the indigenous populations of Canada, the United States, Australia, and New Zealand. Semin Arthritis Rheum, 2017. 46: p. 675-686.

8. Davatchi, F., et al., Epidemiology of rheumatic diseases in Iran from analysis of four COPCORD studies. Int J Rheum Dis, 2016. 19: p. 1056-1062.

9. Uhlig, T., R.H. Moe, and T.K. Kvien, The Burden of Disease in Rheumatoid Arthritis. PharmacoEconomics, 2014. 32: p. $841-851$.

10. Lundkvist, J., F. Kastäng, and G. Kobelt, The burden of rheumatoid arthritis and access to treatment: health burden and costs. Eur J Health Econ, 2008. 8: p. 49-60. 
11. Birnbaum, H., et al., Societal cost of rheumatoid arthritis patients in the US. Curr Med Res Opin, 2010. 26: p. 77-90.

12. Yazdany, J., et al., Coverage For High Cost Specialty Drugs for Rheumatoid Arthritis in Medicare Part D. Arthritis Rheumatol, 2015. 67: p. 1474-1480.

13. Huscher, D., et al., Evolution of cost structures in rheumatoid arthritis over the past decade. Ann Rheum Dis, 2015. 74: p. 738-745.

14. O'Dell, J.R., Therapeutic strategies for rheumatoid arthritis. New England Journal of Medicine, 2004. 350: p. $2591-2602$.

15. Criscione, L.G. and E.W.S. Clair, Tumor necrosis factor-a antagonists for the treatment of rheumatic diseases. Current opinion in rheumatology, 2002. 14: p. 204-211.

16. Dogra, S. and G. Khullar, Tumor necrosis factor-a antagonists: Side effects and their management. Indian J Dermatol Venereol Leprol, 2013. 79 Suppl 7: p. S35-46.

17. Schoels, M., et al., Economic aspects of treatment options in rheumatoid arthritis: a systematic literature review informing the EULAR recommendations for the management of rheumatoid arthritis. Ann Rheum Dis, 2010. 69: p. $995-1003$.

18. American Diabetes Association. Economic Costs of Diabetes in the U.S. in 2017. Diabetes Care, 2018. 41: p. $917-928$.

19. Liljas, B., How to calculate indirect costs in economic evaluations. Pharmacoeconomics, 1998. 13: p. 1-7.

20. Details of workers' wages in 2019.

21. Drummond, M. and G. Stoddart, Economic analysis and clinical trials. Control Clin Trials, 1984. 5: p. 115-128.

22. PPP conversion factor, GDP (LCU per international S) - Iran, Islamic Rep. World Bank.

23. Iran Statistic Centre

24. Mojahedian, M.M., et al., Estimating the Cost of IIIness of Prostate Cancer in Iran. Clin Ther, 2019. 41: p. 50-58.

25. Baker, K.F. and J.D. Isaacs, Novel therapies for immune-mediated inflammatory diseases: What can we learn from their use in rheumatoid arthritis, spondyloarthritis, systemic lupus erythematosus, psoriasis, Crohn's disease and ulcerative colitis? Ann Rheum Dis, 2018. 77: p. 175-187.

26. Hsieh, P.-H., et al., Economic burden of rheumatoid arthritis: a systematic review of literature in biologic era. Ann Rheum Dis, 2020. 79: p. 771-777.

27. Mennini, F.S., et al., Economic Burden of Rheumatoid Arthritis in Italy: Possible Consequences on Anti-Citrullinated Protein Antibody-Positive Patients. Clin Drug Investig, 2017. 37: p. 375-386.

28. GDP, PPP (current international S) - Iran, Islamic Rep. World Bank.

29. Current health expenditure (\% of GDP) - Iran, Islamic Rep. World Bank.

30. $\mathrm{Hu}, \mathrm{H}$., et al., Burden of rheumatoid arthritis from a societal perspective: A prevalence-based study on cost of this illness for patients in China. Int J Rheum Dis, 2018. 21: p. 1572-1580.

31. Malhan, S., et al., The cost of care of rheumatoid arthritis and ankylosing spondylitis patients in tertiary care rheumatology units in Turkey. Clin Exp Rheumatol, 2012. 30: p. 202-207. 
32. Ruof, J., et al., Costs of rheumatoid arthritis in Germany: a micro-costing approach based on healthcare payer's data sources. Ann Rheum Dis, 2003. 62: p. 544-549.

33. Hamuryudan, V., et al., Direct and indirect healthcare costs of rheumatoid arthritis patients in Turkey. Clin Exp Rheumatol, 2016. 34: p. 1033-1037.

34. Michaud, K., et al., Direct medical costs and their predictors in patients with rheumatoid arthritis: a three-year study of 7,527 patients. Arthritis Rheum, 2003. 48: p. 2750-2762.

35. Naqvi, A.A., et al., Estimation of direct cost of managing rheumatoid arthritis treatment to Pakistani patients using realworld follow-up data. Int J Rheum Dis, 2020. 23: p. 325-333.

36. Catay, E., et al., Cost of rheumatoid arthritis in a selected population from Argentina in the prebiologic therapy era. Clinicoecon Outcomes Res, 2012. 4: p. 219-225.

37. Xu, C., et al., Societal costs of rheumatoid arthritis in China: a hospital-based cross-sectional study. Arthritis Care Res (Hoboken), 2014. 66: p. 523-531.

38. Osiri, M., A. Maetzel, and P. Tugwell, The economic burden of rheumatoid arthritis in a developing nation: results from a one-year prospective cohort study in Thailand. J Rheumatol, 2007. 34: p. 57-63.

39. Zhu, T.Y., L.-S. Tam, and E.K. Li, Societal costs of rheumatoid arthritis in Hong Kong: a prevalence-based cost-of-illness study. Rheumatology (Oxford), 2011. 50: p. 1293-1301.

40. Filipovic, I., et al., Quantifying the economic burden of productivity loss in rheumatoid arthritis. Rheumatology (Oxford), 2011. 50: p. 1083-1090.

\section{Figures}

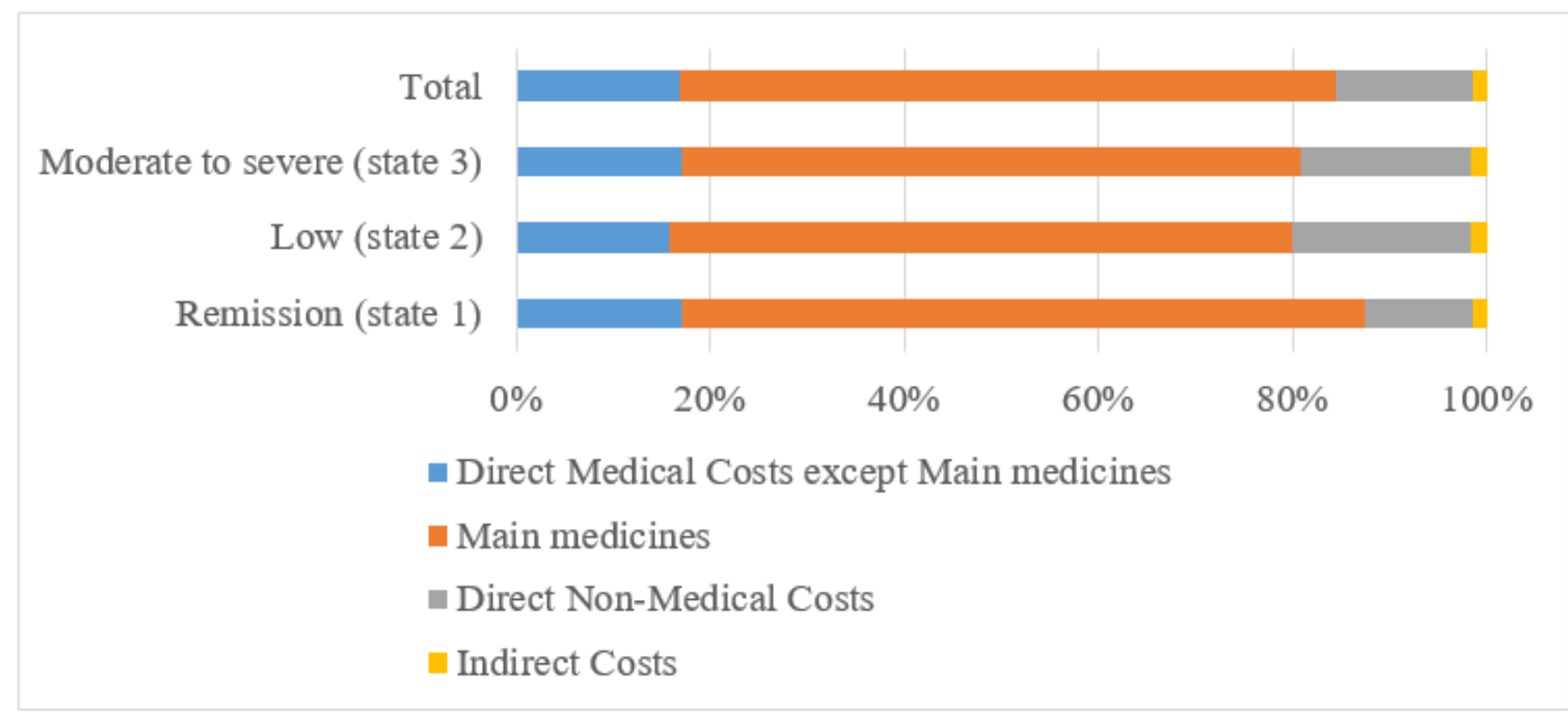

\section{Figure 1}

Costs of each patient with RA in different disease states (Remission, Low, Moderate to Severe, and Total) 


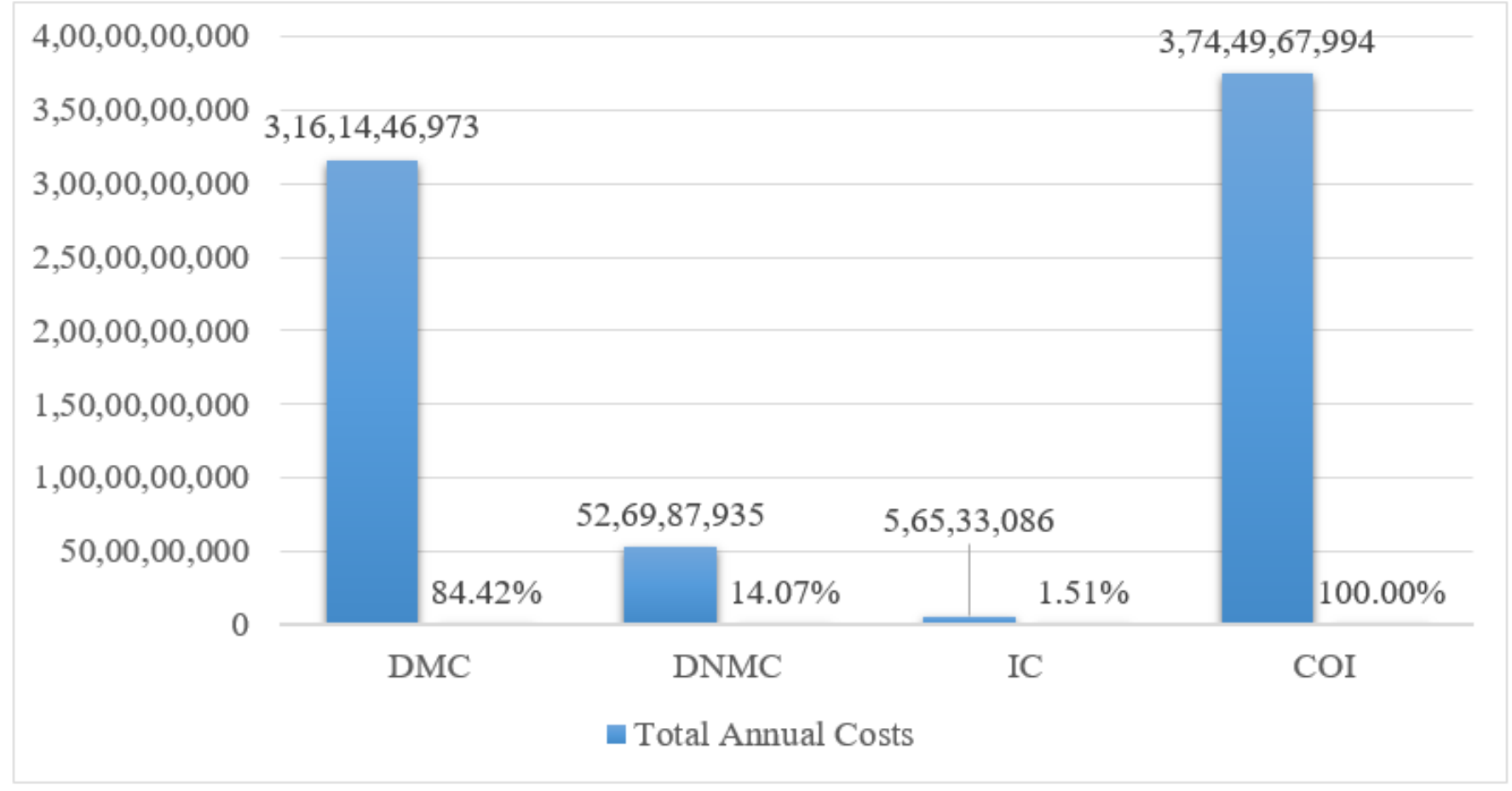

Figure 2

DMC, DNMC, IC and COI of the patients with RA in Iran in 2019 